\title{
Representações da cidade e a denúncia da realidade urbana: espaço e sociedade na músi- ca de Fito Paez
}

\section{Adriana Pozzani de La Vielle e Silva}

Acadêmica do curso de Geografia ( $3^{\circ}$ semestre) no Instituto de Geociências da Universidade Federal do Rio Grande do Sul (UFRGS) e integrante do Projeto de Pesquisa Saberes sobre o Espaço, coordenado pelo Prof. Dr. Mario Lahorgue. E-mail: adriana.lavielle@ufrgs.br

Recebido em 04/2012. Aceito para publicação em 12/2012.

Versão online publicada em 01/02/2013 (http://seer.ufrgs.br/paraonde)

\begin{abstract}
Resumo - A cidade é um tema muito frequente na música do cantor argentino Fito Paez. 0 espaço urbano aparece como palco das mais diversas situações fantasiadas e/ou denunciadas pelo eu-lírico. Diante disso, o presente trabalho discute as diferentes formas de representação da cidade, através da análise de três letras de música produzidas por Paez. À luz da Geografia, a discussão evidencia que é impossível dissociar espaço e sociedade ao pensar a cidade e o urbano, sobretudo porque cada qual só existe em função de suas complexas relações com os demais. As análises mostram que a música, mais do que um veículo para ressignificar a realidade, é também um poderoso instrumento de denúncia das muitas mazelas sociais que caracterizam a realidade urbana contemporânea de grandes cidades como Buenos Aires.
\end{abstract}

Palavras-chave: Geografia. Espaço Urbano. Argentina.

\section{Introdução}

A cidade é um tema bastante recorrente nas letras do cantor argentino Fito Paez, nas quais o espaço urbano aparece como palco das mais diversas situações imaginadas e/ou denunciadas pelo eu-lírico. Diante disso, o presente trabalho analisa as formas de representação da cidade na música do referido cantor, perguntando-se: como a cidade é ali representada? Como o sujeito usa a música para expressar sua relação com o espaço urbano ${ }^{2}$ ?

O objetivo desta reflexão consiste em mostrar a funcionalidade da música na discussão de temas da Geografia, considerando-se essencialmente letras que, de algum modo, discursivizam o espaço geográfico (no presente caso, o urbano). É já bastante conhecido que letras de RAP (ou: Rithm And Poetry) e de Hip Hop costumam ser, por excelência, instrumentos de denúncia das mazelas sociais; no entanto, essa denúncia pode também se concretizar por meio de outros estilos musicais, como por exemplo o Pop-rock de PAEZ.

Para um maior entendimento das relações existentes entre o espaço geográfico e a sociedade que o conforma e habita, convém inicialmente resgatar, de modo breve, alguns pressupostos teóricos em torno desse tema. Tais pressupostos vêm na seção a seguir, a fim de que o leitor eventualmente não familiarizado com o campo teórico da Geografia possa compreender, ainda que seja em linhas muito gerais, o porquê da indissociabilidade entre espaço e sociedade.

\section{Espaço e sociedade: uma relação inextricável}

De maneira bastante resumida, pode-se dizer que o espaço, objeto de estudo da Geografia, é concebido nesta ciência como sendo algo social (SANTOS, 2004), histórico, político, conformado sob relações de poder (RAFFESTIN, 1993) e marcado pela dimensão do vivido (CARLOS, 2007). Dada a temática do presente trabalho, é interessante destacar também uma definição apresentada por MASSEY (2009, p.15). Segundo essa autora, o espaço "modula nossos entendimentos do mundo, nossas atitudes frente aos outros, nossa política" e afeta o modo "como abordamos as cidades e desenvolvemos e praticamos um sentido de lugar" (idem).

As diferentes formas de organização do espaço habitado, em cada época sócio-histórica, resultam de todo um trabalho humano que vai se 
sobrepondo no decorrer das gerações. Porém, ao mesmo tempo em que o homem conforma o espaço, este, por sua vez, "responde" conformando os modos de seu uso pelo homem, uma vez que a maneira pela qual se realiza todo o trabalho humano sobre o espaço (sobretudo na questão da acessibilidade, para citar aqui um exemplo) passa a condicionar qualquer ação humana posterior sobre o mesmo.

O espaço é, portanto, indissociável da sociedade que o habita e o conforma, visto que não só a espacialidade é uma condição sine qua non da produção/ reprodução da sociedade, como esta última é igualmente uma condição sine qua non da produção/reprodução do espaço.

Quando se fala em produção/ reprodução do espaço, é importante lembrar que este não é (re)produzido nos mesmos padrões em que o seria uma mercadoria qualquer. 0 espaço é ocupado/ transformado através de atividades sociais; a sua configuração histórica é resultado dessas atividades, e isso o faz muito diferente de outros produtos (por exemplo, um computador), como logo se pode constatar.

Social por excelência, o espaço urbano se torna mercadoria inserida nos modos de produção capitalistas, e até nisso ele tem as suas especificidades, já que afinal de contas: "il enveloppe les choses produites, il comprend leur relations dans leur coexistence et leur simultanéité: ordre (relatif) et/ou désordre (relatif). Il résulte d'une suite et d'un ensemble d'opérations, et ne peut se réduire à un simple objet" (LEFEBVRE, 1974, p.88).

É essencial, portanto, compreender que o espaço urbano é condição, produto e palco de inúmeras transformações geográficas, sociais, econômicas, culturais, políticas, que, em diferentes escalas e conjunturas, decorrem do desenvolvimento geo-histórico (e aliás, sempre desigual) do capitalismo. Por outro lado, lembre-se com LAHORGUE (2004, p.191) que "o próprio caráter contraditório do capitalismo oferece a possibilidade da existência de movimentos e políticas que questionem a predominância do valor de troca nas relações sociais". Diante disso, para questionar as contradições do capitalismo, a música pode ser - e de fato o é um poderoso instrumento, dada a sua capacidade de transcender as fronteiras físicas dos territórios e alcançar multidões nas mais diversas localidades do planeta, ainda mais na atualidade, com o avanço da comunicação via rede mundial de computadores.

Interessando aqui o espaço urbano capitalista, é válido trazer de LAHORGUE (idem) que "assim como o locus privilegiado da re-produção capi- talista é o espaço urbano, da mesma maneira o locus privilegiado da contradição e da possibilidade de contestação também é o espaço urbano". Sendo produto de inter-relações, o espaço urbano traz em si constitutivamente (ou indissociavelmente) a pluralidade e a contradição, a unidade e a dispersão, o local e o global; a sobreposição de fluxos e de trajetórias, de possibilidades, concretizações elimitações.

\section{Materiais e métodos}

Foram selecionadas para este trabalho três músicas do cantor argentino Fito Paez, a saber: "Ciudad de pobres corazones", "El diablo de tu corazón" e "La nave espacial", que vieram a público em distintos momentos da carreira de PAEZ: a primeira foi lançada no disco homônimo (1987); a segunda está em Rey Sol (2000) e a terceira é de Confiá (2010).

Como material complementar, foram mobilizadas imagens de satélite oriundas da Divisão de Geração de Imagens (DGI) do Instituto Nacional de Pesquisas Espaciais (INPE). A imagem CBERS2B/HRC (Banda Pan), de 13 jun. 2008, refere-se à cidade de Buenos Aires; já a imagem IRS_P6/ LISS_III, de 11 fev. 2010, refere-se à região do rio Paraná, onde se situam as cidades de Corrientes, Barranqueras e Resistencia. E também foram utilizadas fotografias de domínio público disponíveis na mídia eletrônica (sites UOL e Google), para caracterizar um exemplo de Villa Miseria portenha, bem como a praia brasileira de Ipanema, mencionada em uma das letras analisadas.

\section{Entre a fantasia e a realidade}

$\mathrm{Na}$ medida em que interessam aqui as representações da cidade que aparecem na música do argentino PAEZ, dividiremos as análises a seguir em três blocos, discutindo em cada um deles uma canção diferente. Sendo assim, o item 2.1 analisará a música"El diablo de tu corazón"; o 2.2 discutirá "La nave espacial" e por fim o item 2.3 discutirá "Ciudad de pobres corazones".

\subsection{Espaço e crítica social}

Vejamos primeiramente a letra de "El diablo de tu corazón", originalmente lançada em 2000. Na letra desta canção, o eu-lírico canta à cidade - no caso, Buenos Aires - como se esta fosse sua mulher amada, à qual aliás ele se dirige de um modo extremamente carinhoso (por ex.: "nena", "amor").

Essa letra é muito rica por toda a crítica 
social que traz subjacente, e portanto, possibilita boas reflexões sobre a realidade urbana de Buenos Aires do início do século XXI, realidade essa também contraposta (pelo sujeito) com a dos anos 80 do século XX:

\author{
Ey qué te pasa Buenos Aires, es con vos... \\ No es la techno ni el rock \\ Es tu parte que vos no conoces \\ Cuidado la conozco yo \\ Sabés que va a ser lo mejor \\ Cuando estes así \\ Sacate el diablo de tu corazón \\ [...] Hace un tiempo en esta misma ciudad \\ Allá en los comienzos de los años ochenta \\ El mundo aún se podía mover \\ Estaban altas las defensas \\ No se comía tanta mierda \\ Buenos Aires hoy te falta mambo \\ Te sobra muerte y pasarela. [...]
}

Valendo-se da figura de linguagem chamada propopopeia (ou personificação), o eu-lírico se dirige à cidade através de um diálogo, por meio do qual vai permitindo que seja revelada a realidade urbana passada e presente de Buenos Aires: a cidade que não se conhece totalmente; que tem ao lado do tradicional tango também o rock e a música eletrônica (techno); a cidade que pode ser melhor se tirar do seu "coração" a maldade. Cidade de concreto onde são abundantes as "passarelas" e também, como em qualquer outra grande cidade da Argentina ou de outros países, onde são abundantes os episódios de descaso para com a vida humana ("te sobra muerte"...).

Quanto à retrospectiva que nos remete à Buenos Aires dos anos 80 do século XX, cabe questionar quando se diz "en esta misma ciudad". Seria de fato a "mesma" cidade? Uma cidade que se transforma com o decorrer do tempo pode ainda ser considerada a "mesma"? Evidentemente não, pois como se sabe, os modos de produção/reprodução/ transformação do espaço urbano, por meio da ação humana evidentemente, engendram sempre conformações singulares, irrepetíveis em outras localidades e até mesmo em outras épocas, se for considerada uma única localidade.

Entre essas transformações podem ser citadas aquelas decorrentes da instalação de transnacionais; sem esquecer aqui a discussão quanto aos efeitos destas sobre a população, como fica bem claro no verso "no se comía tanta mierda", o qual alude à alimentação do tipo fast-food, que é hoje cada vez mais consumida nas grandes cidades e que é também uma das responsáveis pelo aumento dos casos de obesidade, diabetes etc. Nesse sentido, aspectos da dinâmica econômica mundial fazem um eco nessa breve rememoração do sujeito. Fundada no século XVI (precisamente em 1536, mas refundada em 1580), Buenos Aires consiste atualmente, junto com sua região metropolitana, na 3ํㅡ maior aglomeração urbana da América Latina, tendo mais de 13 milhões de habitantes. Para que a cidade não fosse confundida com a província homônima, a Constituição da Cidade estabeleceu, em 1996, o nome "Ciudad Autónoma de Buenos Aires" (também conhecida como CABA).

A cidade de Buenos Aires é um importante centro cultural no cenário latino-americano; e seu setor terciário é o mais importante da economia, representando cerca de $78 \%$ do PIB de Buenos Aires. Aliás, em 2008, esse PIB respondeu por cerca de $43 \%$ do PIB argentino do mesmo ano.

A figura 1, a seguir, é uma imagem orbital capturada pelo satélite CBERS-2B e caracteriza a referida cidade, tendo sido obtida através do catálogo de imagens do INPE (o qual, vale dizer aqui, disponibiliza também imagens orbitais de outras localidades, e não só de cidades brasileiras).

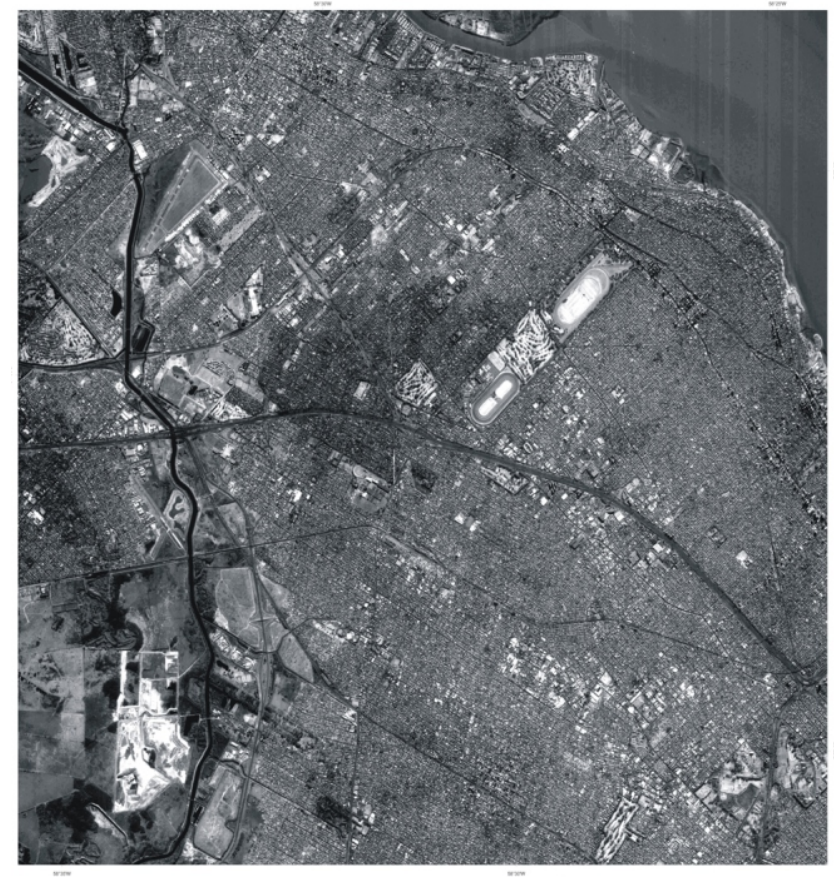

Fig.1. Imagem orbital CBERS-2B/HRC de Buenos Aires. Fonte da imagem: DGI- INPE

Avançando, apresenta-se abaixo mais um fragmento da canção "El diablo de tu corazón":

[...] No me pidas que me porte cool

No me metas tensión

Te haces la chica sin tabús

Pero sufrís baja presión

Sabés que va a ser lo mejor

Aprendé de míque soy un chico pobre

De allá del interior 
Juguemos nena

Peliemos nena

Bancátelo

Buenos Aires sí

Sacate el diablo de tu corazón (de tu corazón)

Porque aquí y en todas partes hay

Pibes en el balcón

También hay pibes en un cajón

Y hay mucha rabia suelta

Yangustia nena

Yhay mucha mucha desesperación

[...] Por qué nos cuesta tanto el amor

Yo quiero ver tu risa

Ybesar tu boca

Y sacarte el diablo de tu corazón. [...]

A cidade que se pretende moderna e "descolada" ("sin tabús") pode ser bem melhor se souber aprender com a sua população, especialmente a população interiorana e pobre que para lá emigra e comumente se torna vítima da segregação espacial.

Historicamente, existem desde o século XIX muitas villas misérias na cidade, em geral (mas não apenas) concentradas nas zonas Sul e Central. Um exemplo muito conhecido é a Villa Miseria 31, em Buenos Aires, representada na figura 2, a seguir. Nesta vila (ou favela, como se diz no Brasil), verifica-se uma absurda precariedade no fator infraestrutura urbana, visto que os moradores carecem da qualidade em serviços públicos fundamentais como, por exemplo, saneamento básico, assistência à saúde, iluminação pública, transporte escolar, etc. Muitas pessoas morrrem devido ao fato de que as unidades móveis de atendimento médico se recusam a entrar nas villas misérias, e essa recusa na prestação do serviço acontece seja pelo medo da violência, seja por um preconceito social.

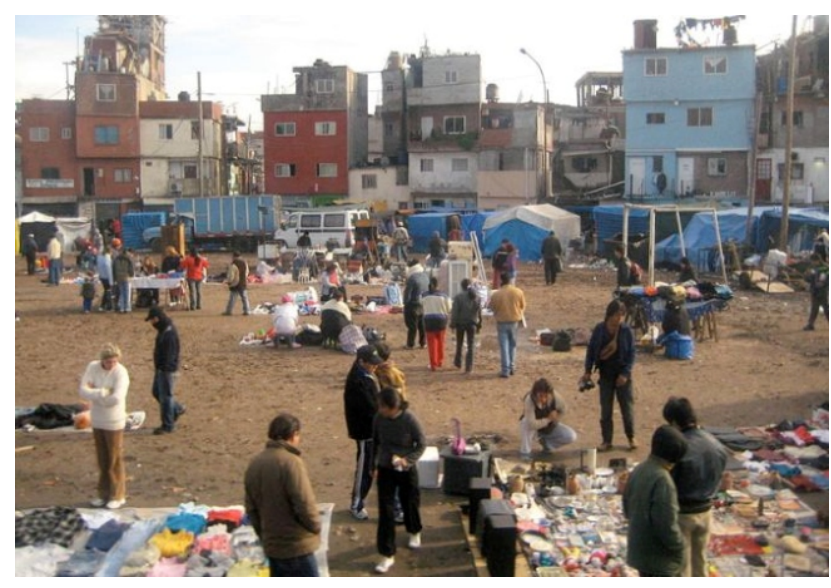

Fig.2. Villa miseria 31, em Buenos Aires. Fonte da imagem: UOL
Boa parte dessas favelas decorrem da questão migratória, notadamente em razão de fatores de expulsão populacional tais como a modernização do campo, mas também em virtude da chegada de imigrantes europeus que ali se instalaram, e até mesmo da crise econômica que intensificou as desigualdades sociais e os assentamentos informais.

Aqui é relevante mencionar que, como diz GOTTDIENER (1997), a própria produção do espaço consiste em "um elemento a mais na natureza antagônica das relações sociais capitalistas", o que, no entanto, não significa que seu funcionamento esteja diretamente evidente nas formas urbanas. Muito pelo contrário: é bem típico do sistema capitalista dissimular as desigualdades das quais ele se nutre, de maneira que a dominação será tanto mais eficiente quanto maior for a sua capacidade de aparecer como algo "natural" (e não como algo imposto arbitrariamente) no funcionamento da vida urbana, no cotidiano das pessoas que habitam a cidade e/ou que nela trabalham.

Voltando à música, é dito ali que existe desigualdade social na cidade, e que há raiva, angústia e desespero em toda parte. Há também, notadamente, a revolta daquela fração populacional impossibilitada de "apaixonar-se" "Yo quiero ver tu risa / Y besar tu boca”) pela cidade, em razão de que lhe é subtraído o efetivo direito à mesma.

Nesse sentido, ter um "caso de amor" com a cidade é poder desfrutá-la em seu valor de uso (tal como o entende LEFEBVRE, 1978). E se é tão difícil a relação de amor com a cidade, isso se deve às contradições do sistema capitalista, em que pese o predomínio do valor de troca (idem), que subjuga o valor de uso, ao mesmo tempo em que dita as regras (capitalistas) desse uso.

Sujeito e cidade serão felizes juntos quando o valor de uso predominar sobre o valor de troca no espaço urbano, e quando for extraída deste último a maldade gerada pelo sistema capitalista às classes sociais exploradas, e então todas as classes sociais (sobretudo a classe dos pobres e imigrantes, e não exclusivamente a dominante) poderão verdadeiramente amar sua cidade e vê-la "sorrir".

É necessário, portanto, devolver ao sujeito o seu direito histórico de usar o espaço, em vez de apenas lhe impor o de consumi-lo. Se a relação sujeito-espaço não for repensada no interior do sistema capitalista, o espaço continuará sendo o palco das desigualdades sociais, e a classe dominante prosseguirá sendo sua grande reforçadora. Ocorre que como diz SANTOS (2009, p.68):

Pobreza e riqueza são realidades antagônicas, embora complementares, pois uma não pode existir sem a outra. 0 
problema de eliminar a pobreza, isto é, de suprimir as diferenças de renda criadas por um processo produtivo gerador de desigualdades, supõe uma mudança no próprio processo produtivo, o que vale dizer, das relações do homem com a natureza e dos homens entre si. É inútil imaginar que a pobreza poderá ser eliminada sem a modificação da atual estrutura da produção, dos investimentos e do consumo.

Palco das contradições do capitalismo, o espaço urbano só pode ser pensado relacionalmente. Segundo LEFEBVRE (2008, p.157), "o urbano como forma e realidade nada tem de harmonioso". E mais: "Ele também reúne os conflitos. Sem excluir os de classes. 0 urbano se apresenta [...] como lugar dos enfrentamentos e confrontações, unidade das contradições".

Lembre-se também que, de acordo com LAHORGUE (2004, p.10), "ainda que o urbano não seja um em-si isolado do mundo, é no espaço construído das cidades que boa parte das contradições e conflitos do capitalismo tem lugar".

Veja-se a seguir mais um trecho da letra de "El diablo de tu corazón":

\section{[...] No te asustes Buenos Aires no \\ No te asustes amor \\ Las cosas tienen que estar bien \\ Ya no se puede estar peor \\ Las cosas van a estar mejor \\ Vas a ser felíz \\ Sacate el diablo de tu corazón \\ Buenos Aires sí \\ Cortála mufa de tu corazón \\ Buenos Aires sí \\ Vayamos juntos a patear el sol. [...]}

Na visão do eu-lírico, a situação caótica da cidade já chegou ao grau máximo, mas o caos pode acabar se algo for feito para que seja tirado da cidade o "diabo" que impossibilita a felicidade de todos e, principalmente, que impede uma efetiva reforma urbana que assegure às camadas menos favorecidas economicamente o seu direito à cidade, enfim, que lhes assegure a "justiça social" (HARVEY, 1980).

\subsection{Espaço e simulacro de cidade}

Avançando para a análise da letra de "La nave espacial" (2010), será possível constatar que o fantástico também comparece na recriação do espaço urbano, ou mais pontualmente, na representação de um simulacro de cidade. Quanto a isso, a referida canção explora significativamente essa dimensão, ao engendrar uma situação inusitada onde a cidade brasileira do Rio de Janeiro desaparece graças a um suposto tsunami:
[...] No le dijeron nada a nadie
Y se fueron a Niteroi
El viaje fue divino por las rutas argentinas
Durmieron en la calle, en las Shells y en un camión
Tomaron colectivos y en Clorinda
Cruzaron el rio con dos malandras [...]
Querían ver a la nave espacial de Niemayer
Que vieron el domingo en la revista de Clarín
La noche que llegaron a Ipanema se tiraron a dormir
Entonces pasó lo que pasó
El mar se puso bravo
Levantaron olas de 1200 metros
Y así fue que Rio de Janeiro desapareció.

O eu-lírico narra uma situação em que o sujeito abandona a família e migra clandestinamente com a amante para o Rio de Janeiro, na intenção de não voltar mais. Não será colocada em questão, aqui, a referência à "nave espacial" de Niemayer, nem alguma suposta ligação semântica que o sujeito teria estabelecido entre a mesma e a "Torre Espacial" portenha (construção de 220 metros, situada no interior de um parque).

Interessa perceber que a letra dessa música permite pensar na criação de um simulacro do Rio - o que, aliás, é típico da indústria turística - e permite, também, explorar o fato de que informações a respeito de acontecimentos de outros países ultrapassam fronteiras físicas graças à mídia (veja-se a referência feita a El Clarín) e assim alcançam outros territórios, sobretudo quando se atrelam à indústria do turismo, fato incontestável em se tratando da cidade do Rio de Janeiro.

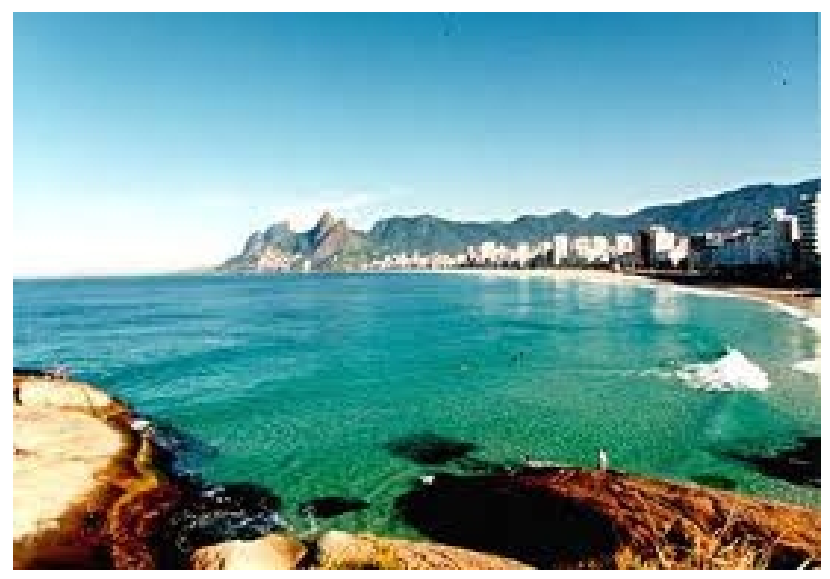

Fig.3. Praia de Ipanema, na cidade do Rio de Janeiro - RJ. Fonte da imagem: Google 
Como sabemos, a indústria do turismo, em qualquer lugar, é um dos meios pelos quais a relação Estado-mercado contribui para a transformação de determinadas cidades (ou regiões dela) em efetivos "simulacros de lugar". Vendem-se supostos sentidos de lugar e supostas possibilidades de identificação dos sujeitos com ele; reorganiza-se o espaço urbano em função dessa lógica, a despeito dos interesses e necessidades reais da população "nativa", os quais ficam em segundo plano.

A atividade turística, sendo uma indústria de criação de "não-lugares" (CARLOS, 2007) - anunciados e vendidos como simulacros de efetivos lugares - transforma radicalmente o espaço urbano, gerando uma segregação e uma identificação maior dos moradores com o bairro, não com a área turística. Mais que isso, hoje se vende o espaço para o cidadão usufruir (ou melhor dizendo, consumir) seu direito ao lazer.

Outros temas que podem ser pensados a partir dessa canção consistem nos seguintes: a) a entrada ilegal de imigrantes em países estrangeiros (a partir da narração de como os personagens procederam para sair da Argentina e chegar ao Brasil); b) as questões ambientais contemporâneas, sobretudo as de ordem climática, evocadas pela situação fantasiosa na qual uma onda gigante "engole" a cidade do Rio de Janeiro sem que os personagens possam fazer qualquer coisa para impedir tal acontecimento.

Uma vez que se transcenda então a fantasia construída na letra de "La nave espacial", fica a questão de pensar em quão impotentes, muitas vezes, são os sujeitos diante de fatos e transformações cuja ocorrência eles não podem evitar, e que afetam radicalmente sua relação com o espaço urbano.

Por outro lado, a população não é algo que simplesmente está sobre o espaço geográfico; ela também é agente de transformações geo-históricas do/no espaço, tendo assim o poder potencial de organizar-se para lutar pela modificação da realidade urbana que se lhe apresenta, toda vez em que esta lhe materializa a privação do direito ao uso compartilhado do espaço, a privação da justiça social, enfim, a privação do direito à própria cidade.

\subsection{Espaço e lugar na cidade}

Para este terceiro e último item, será mobilizado um trecho da canção "Ciudad de pobres corazones" (1987), como se podeler a seguir:

En esta puta ciudad

Todo se incendia y se va

Matan a pobres corazones

En esta sucia ciudad
No hay que seguir ni parar Ciudad de locos corazones [...] No quiero salir a fumar No quiero salir a la calle con vos

[...] Dicen que ya no soy yo

Que estoy mas loco que ayer

Y matan a pobres corazones. [...]

Em nota no encarte do CD Euforia (1996), onde a canção foi relançada, PAEZ afirma o seguinte: "Esta es una de las canciones que jamás hubiera querido tener que escribir. Maldita en su naturaleza, a raiz del asesinato de mi abuela Belia, mi tía abuela Pepa y la chica que trabajava en casa embarazada de siete meses en noviembre del ' 86 ".

Até o momento, não foi possível obter uma referência a respeito de qual cidade é essa referida pela música, mas o que se sabe é que Fito Paez é natural de Corrientes (na Argentina). Em sua música, trata-se de uma cidade das impermanências e sujeiras, dos loucos corações, cidade amaldiçoada pelo eu-lírico.

A figura 4, adiante, caracteriza a região situada às margens do rio Paraná, na qual se situam as cidades de Corrientes (à direita) e de Barranqueras e Resistencia (ambas à esquerda). Nessa imagem orbital IRS_P6/LISS_III, elaborada pelo INPE em composição colorida RGB-543, a área urbana pode ser observada em tons de magenta.

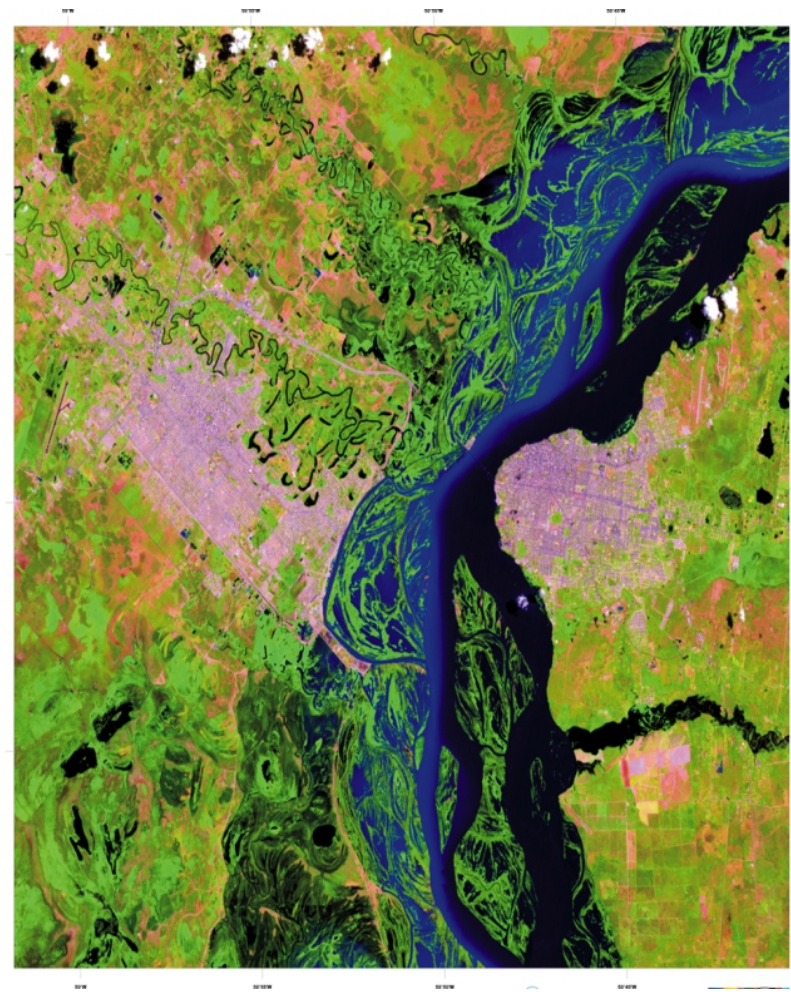

Fig.4. região de Corrientes, situada à direita da imagem, às margens do curso de água em destaque. Fonte da imagem: DGI-INPE. 
Porém, à luz de um ponto de vista geográfico, não interessam aqui as questões subjetivas individuais, que seriam assunto para abordagens de natureza psicológica, e sim o modo através do qual a cidade é representada na música. É verdade que os versos de "Ciudad de pobres corazones" parecem de fato confirmar a "maldição" que, no caso em tela, o eu-lírico despeja sobre o espaço urbano, fazendo com que este último se lhe apareça também como algo maldito em função de um acontecimento traumático do qual tal espaço foi o palco, a saber, $\mathrm{o}$ assassinato de parentes.

O que interessa aqui, no entanto, é a dimensão do coletivo, que permite entrever na música a crítica à violência urbana e o fato de que a rua historicamente um espaço de encontros por excelência - agora se torna o lugar de um convívio negado, reforçado através de "no quiero salir a la calle con vos".

Como se sabe, a rua é uma parcela pública do espaço, hierarquizada como tal. Graças a ela se interconectam unidades territoriais, sejam estas públicas ou privadas. A função primeira da rua sempre foi promover essa ligação e a convivência entre as pessoas; porém, o advento do capitalismo e o crescimento da indústria automobilística, aliados às políticas comerciais de crédito e financiamento, contribuíram para que tal espaço público se tornasse majoritariamente algo que existe em virtude da (e para a) circulação de veículos.

$\mathrm{Na}$ atualidade, parece algo muito natural que a rua seja para toda sorte de veículos passarem. Esses mesmos veículos que configuram o trânsito caótico de grandes cidades, geralmente impedem que as pessoas transitem pela rua, que se sentem nos arredores (calçadas) para conversar e olhar a paisagem, atitudes estas que, aliás, são impensáveis em boa parte das áreas metropolitanas. Na agitação das grandes cidades, a rua deixou de ser o lugar de encontro, para se tornar um lugar de passagem de carros, caminhões, pessoas, trens que a cortam, etc.

Em que pese a questão da rua, lembre-se que o lugar é uma porção espacial que só adquire real significado para o sujeito em razão de vivências que se criam ali (CARLOS, 2007) com pessoas, coisas e até com o espaço propriamente dito. Uma cidade na íntegra não é um lugar; já o lugar, por algum motivo, se torna algo cotidianamente frequentado (o bairro, a praça, a rua etc.). A conformação dessa porção espacial, desse lugar, é ao mesmo tempo individual e coletiva, mas acima de tudo coletiva.

As representações do espaço urbano analisadas aqui, são construídas como uma espécie de mosaico, onde diferentes representações de lugares se juntam para formar conjuntos de singularidades e de contradições, que são as cidades.

\section{Conclusão}

À luz da Geografia, porém com uma linguagem acessível também aos leitores identificados com outras áreas do conhecimento, tais como a Música e a Literatura, o presente trabalho buscou analisar a realidade urbana tal como ela se materializa na música de Fito Paez, a partir das diferentes representações de cidade.

Através das análises, tornou-se evidente que a música, de modo geral, mais que um veículo para recriar a realidade segundo as mais variadas maneiras, pode também ser um poderoso instrumento de denúncia das muitas mazelas sociais que caracterizam a realidade urbana contemporânea das grandes cidades, notadamente em virtude de sua capacidade de alcançar grandes contingentes de pessoas em escala internacional. No caso aqui analisado, vale lembrar que Paez é um cantor que já tem uma longa trajetória musical e que faz shows em várias cidades do mundo.

Diante de tudo quanto precede, é bastante fácil confirmar aqui a impossibilidade de dissociar espaço e sociedade ao pensar a cidade e o urbano, sobretudo porque cada qual só existe em função das complexas relações estabelecidas com os demais, inclusive em casos específicos nos quais a dimensão do imaginado se sobrepõe à do real, como acontece em alguns trabalhos artísticos.

\section{Referências}

CARLOS, A. F. A. O lugar no/do mundo. São Paulo: Labur, 2007.

GOTTDIENER, M. A produção social do espaço urbano. 2.ed. São Paulo: Edusp, 1997.

HARVEY, D. A justiça social e a cidade. São Paulo: Hucitec, 1980.

INSTITUTO NACIONAL DE PESQUISAS ESPACIAIS (INPE). Imagem CBERS-2B de Buenos Aires (parcial 1) - Argentina. Disponível em: <http:// www.dgi.inpe.br>. Acesso em: 01 dez. 2012.

Imagem IRS_P6 - LISS_III das cidades de Corrientes, Barranqueras e Resistencia (rio Paraná) - Argentina. Disponível em: <http://www.dgi.inpe.br>. Acesso em: $01 \mathrm{dez}$. 2012. 
LAHORGUE, M. L. Espaço e políticas urbanas: Porto Alegre sob governo do Partido dos Trabalhadores. Tese (Doutorado em Geografia). Universidade Federal de Santa Catarina, Florianópolis: UFSC, 2004.

LEFEBVRE, H. A revolução urbana. 3.reimpr. Belo Horizonte: UFMG, 2008.

El derecho a la ciudad. 4.ed. Barcelona: Ediciones Península, 1978.

La production de l'espace. Paris: Éditions Anthropos, 1974.

MASSEY, D. Pelo Espaço: uma nova política da espacialidade. 2.ed. Rio de Janeiro: Bertrand Brasil, 2009.

PAEZ, F. Confiá. Sony Music, 2010.
. Rey Sol. WEA, 2000.

. Ciudad de pobres corazones. EMI, 1987.

RAFFESTIN, C. Por uma Geografia do poder. São Paulo: Ática, 1993.

SANTOS, M. Pensando o espaço do homem. 5.ed. São Paulo: Edusp, 2009.

Por uma Geografia Nova: da crítica da Geografia a uma Geografía crítica. 6.ed. São Paulo: EDUSP, 2004.

UOL. Ambulâncias se recusam a entrar nos bairros mais pobres de Buenos Aires. Disponível em: <http://operamundi.uol.com.br/conteudo/notici as/22072/ambulancias+se+recusam $+a+$ entrar $+n$ os+bairros+mais+pobres+de+buenos+aires.shtml >. Acesso em: 01 dez. 2012.

\title{
City representations and the denouncement of urban reality: space and society in Fito
} Paez's songs

\begin{abstract}
The city is frequently a theme of Fito Paez's songs. The urban space appears in the Argentinean singer's songs as the stage of the most different situations which are imagined and/or denounced by the subject. In face of that, this paper discusses the different ways how the city is represented, by analysing three songs made by Paez. Sustained by Geography, the discussion brings to the light that it is impossible to dissociate space and society when thinking about the city and the urban, principally because each one only exists in function of its complexes connections with the other ones. Our analysis shows that music is more than a vehicle to signify the reality, once it is a powerful instrument to denounce so many social problems which characterizes the contemporanian urban reality of big cities such as Buenos Aires.
\end{abstract}

Keywords: Geography. Urban Space. Argentina.

\section{Representaciones de la ciudad y la denuncia de la realidad urbana: espacio y sociedad en las canciones de Fito Paez}

\begin{abstract}
Resumen - La ciudad es un tema muy común en la música del cantante argentino Fito Paez. El espacio urbano se presenta como un escenario de las más diversas situaciones imaginadas o denunciadas por lo sujeto. Por lo tanto, en este trabajo se analizan las diferentes formas de representación de la ciudad, a través de la análisis de tres liricas producidas por Paez. A la luz de la Geografía, el análisis muestra que es imposible separar el espacio y la sociedad para pensar la ciudad y lo urbano, principalmente porque cada uno sólo existe debido a sus complejas relaciones con los demás. El análisis muestra que la música, más que un vehículo para replantear la realidad, es también un poderoso instrumento de denuncia de los muchos males sociales que caracterizan la realidad urbana contemporánea de las grandes ciudades como Buenos Aires.
\end{abstract}

Palabras-clave: Geografía. Espacio Urbano. Argentina. 